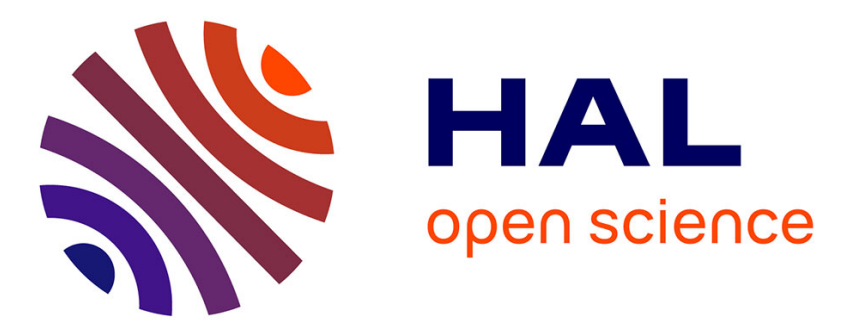

\title{
Evaluation of response to chemotherapy: Work still in progress
}

Anthony Dohan, Philippe Soyer

\section{To cite this version:}

Anthony Dohan, Philippe Soyer. Evaluation of response to chemotherapy: Work still in progress. Digestive and Liver Disease, 2019, 51, pp.1192 - 1193. 10.1016/j.dld.2019.04.003 . hal-03488021

\section{HAL Id: hal-03488021 \\ https://hal.science/hal-03488021}

Submitted on 20 Dec 2021

HAL is a multi-disciplinary open access archive for the deposit and dissemination of scientific research documents, whether they are published or not. The documents may come from teaching and research institutions in France or abroad, or from public or private research centers.
L'archive ouverte pluridisciplinaire HAL, est destinée au dépôt et à la diffusion de documents scientifiques de niveau recherche, publiés ou non, émanant des établissements d'enseignement et de recherche français ou étrangers, des laboratoires publics ou privés.

\section{(c) (1) 3}

Distributed under a Creative Commons Attribution - NonCommercial| 4.0 International 


\section{Evaluation of response to chemotherapy: work still in progress}

DOHAN Anthony, MD, PhD (anthony.dohan@aphp.fr)

Assistance Publique - Hôpitaux de Paris, Cochin Hospital, Radiology A department, Sorbonne Paris Cite, Paris Descartes University, Paris - France

SOYER Philippe, MD, PhD (philippe.soyer@aphp.fr)

Assistance Publique - Hôpitaux de Paris, Cochin Hospital, Radiology A department, Sorbonne Paris Cite, Paris Descartes University, Paris - France

Keywords: tumor response; biomarkers ; RECIST1.1 


\section{Evaluation of response to chemotherapy: work still in progress}

Response to chemotherapy is used as a surrogate biomarker of overall survival in clinical trials. Imaging criteria are classically used to define tumor response, and efforts have been made to gain in reproducibility. In this regard, the simplification of RECIST evaluation with version 1.1 ( 2 lesions per organ and 5 lesions maximum in total) has resulted in great robustness and simplicity of response evaluation [1]. RECIST1.1 criteria are robust and easy to use since they are unidimensional and based on a single-slice approach. They are not very sophisticated, but they form the backbone of both registration trials and clinical practice. Nevertheless, the $30 \%$ threshold retained for response is usually obtained relatively late in the management of patients after multiple cycles of chemotherapy. Many studies have evaluated other imaging biomarkers to provide an early prediction of response to therapy and ultimately patient outcome. The goal of these biomarkers is to better discriminate between long term favorable response and short-term progressive diseases.

In the study by Mazard et al., authors present a new mixed tumor response criterion combining response in size with a threshold of $15 \%$ and decrease in tumor-to-liver density (TTLD) [2]. The authors are not the first ones to combine size criteria and density, which is considered to represent the function of the lesion. Choi et al. already suggested that a combination of decrease in size of $10 \%$ or a decrease in density superior to $15 \%$ overperformed RECIST 1.1 criteria in the evaluation of hypervascular lesions such as gastro intestinal stromal tumors (GIST) or hepatocellular carcinoma (HCC) [3]. The main originality of the study by Mazard et al. is the assessment of TTLD rather than simple density. Interestingly, the idea is to normalize the density of the lesion on the density of surrounding liver in order to reduce the variability in enhancement and possibly to account for interindividual variations. This variability results from different scanning parameters such as time of acquisition relative to the start of intravenous administration of iodinated contrast material, dose and flow rate of injection that may be different from one CT examination to another one. Second, it takes into account the potential changes in surrounding non-tumoral liver parenchyma density under chemotherapy and anti-angiogenic treatment. It is classical in MRI studies to normalize the signal of tumor on surrounding tissue as the intensity of signal at MRI varies significantly among the different acquisition parameters of each sequence, but is less often used at computed tomography (CT)[4]. The approach from Mazard et al. is interesting in, at least, two respects: first it confirms previous works that showed that pretreatment high density tumor on CT is suggestive of good response and better outcome [5]. Second it also provides a combined evaluation of size and function that tumor enhancement indirectly represents. As shown by Chun et al., decrease in enhancement (i.e. hypoattenuating, pseudo-cystic appearance of lesions) is associated with a better outcome and may appear earlier than size response [6]. The ratio with liver parenchyma helps take into account the fatty changes that is frequently observed in patients treated with chemotherapy.

Myriad of studies have evaluated new response criteria to identify or build a model that best predicts overall survival. Multiple thresholds for size response have been tested. The $30 \%$ threshold is not based on large multicentric study and its use is therefore questionable. The early tumor shrinkage, defined as the decrease in the sum of target lesions more than $20 \%$ at 8 weeks has shown promising results [7]. In patients with metastatic colorectal cancer, the 
ultimate objective of earlier assessment of response is to identify very good responders that could benefit from an aggressive approach including surgical resection and very poor responders that will benefit from a switch in therapy. In 2009, Chun et al. have proposed new morphological criteria that have been investigated in several studies $[6,8]$. A recent study has suggested that morphological response may correlate with tumor growth pattern at pathology [9]. Nevertheless, these criteria do not include the shrinkage of the tumors that is known to be a strong predictor of outcome. In addition, the subjective evaluation of these changes may also be a limitation for generalizability. The multiplication of response criteria is also questionable, as a lot of published criteria, even though they are tested in external validation cohorts are never incorporated in clinical practice. Finally, all these response criteria are imperfect, and we can assume that overall survival will remain the primary outcome of clinical trials for a long time until a strong surrogate biomarker enters in clinical practice. Quantitative approaches that are now proposed in radiological workflows will probably allow overcoming this main limitation and build simple, highly reproducible and accurate response criteria. It may be also assumed that artificial intelligence may have a major role in this field in a near future [10].

\section{References}

(1) Eisenhauer EA, Therasse P, Bogaerts J, et al. New response evaluation criteria in solid tumours: revised RECIST guideline (version 1.1). Eur J Cancer. 2009;45:228-47.

(2) Mazard T, Assenat E, Dupuy M, et al. Quantitative evaluation of liver metastases density on computed tomography: a new tool to evaluate early response to bevacizumab containing chemotherapy. Dig Liver Dis. 2019; IN PRESS.

(3) Choi H, Charnsangavej C, Faria SC, et al. Correlation of computed tomography and positron emission tomography in patients with metastatic gastrointestinal stromal tumor treated at a single institution with imatinib mesylate: proposal of new computed tomography response criteria. J Clin Oncol. 2007;25:1753-9.

(4) Soyer P, Kanematsu M, Taouli B, et al. ADC normalization: a promising research track for diffusion-weighted MR imaging of the abdomen. Diagn Interv Imaging. 2013;94:571-3.

(5) Froelich MF, Heinemann V, Sommer WH, et al. CT attenuation of liver metastases before targeted therapy is a prognostic factor of overall survival in colorectal cancer patients. Results from the randomised, open-label FIRE-3/AIO KRK0306 trial. Eur Radiol. 2018;28:5284-92. (6) Chun YS, Vauthey JN, Boonsirikamchai P, et al. Association of computed tomography morphologic criteria with pathologic response and survival in patients treated with bevacizumab for colorectal liver metastases. JAMA. 2009;302:2338-44.

(7) Heinemann V, von Weikersthal LF, Decker T, et al. FOLFIRI plus cetuximab versus FOLFIRI plus bevacizumab as first-line treatment for patients with metastatic colorectal cancer (FIRE-3): a randomised, open-label, phase 3 trial. The Lancet Oncology. 2014; 15:1065-75.

(8) Shindoh J, Loyer EM, Kopetz S, et al. Optimal morphologic response to preoperative chemotherapy: an alternate outcome end point before resection of hepatic colorectal metastases. J Clin Oncol. 2012;30:4566-72.

(9) Frentzas S, Simoneau E, Bridgeman VL, et al. Vessel co-option mediates resistance to anti-angiogenic therapy in liver metastases. Nat Med. 2016;22:1294-302.

(10) Group S-I, Cerf, French Radiology C. Artificial intelligence and medical imaging 2018: French Radiology Community white paper. Diagn Interv Imaging. 2018;99:727-42. 